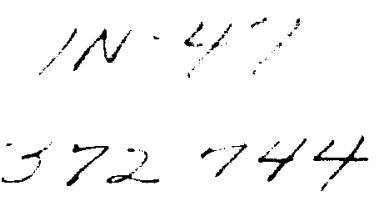

\title{
THE BEHAVIOR OF TOTAL LIGHTNING ACTIVITY IN SEVERE FLORIDA THUNDERSTORMS
}

\author{
Earle Williams \\ Parsons Laboratory \\ Massachusetts Institute of Technology \\ Cambridge, Massachusetts 02139 \\ Bob Boldi, Anne Matlin, and Mark Weber \\ Massachusetts Institute of Technology \\ Lincoln Laboratory \\ Lexington, Massachusetts 02420-9185 \\ Steve Hodanish and Dave Sharp \\ National Weather Service \\ Melbourne, Florida 32935 \\ Steve Goodman, Ravi Raghavan, and Dennis Buechler \\ NASA Marshall Space Flight Center \\ Huntsville, Alabama 35806
}

Submitted to the Special Issue of Atmospheric Research

In Honor of Bernard Vonnegut

July 1998 


\begin{abstract}
The development of a new observational system called LISDAD (Lightning Imaging Sensor Demonstration and Display) has enabled a study of severe weather in central Florida. The total flash rates for storms verified to be severe are found to exceed 60 flashes/min, with some values reaching 500 flashes/min. Similar to earlier results for thunderstorm microbursts, the peak flash rate precedes the severe weather at the ground by 5-20 minutes. A distinguishing feature of severe storms is the presence of lightning "jumps"-abrupt increases in flash rate in advance of the maximum rate for the storm. The systematic total lightning precursor to severe weather of all kinds-wind, hail, tornadoes-is interpreted in terms of the updraft that sows the seeds aloft for severe weather at the surface and simultaneously stimulates the ice microphysics that drives the intracloud lightning activity.
\end{abstract}




\section{INTRODUCTION *}

This study is concerned with the electrification of severe weather, an appropriate topic for this Special Issue in honor of Bernard Vonnegut. The first examination of electrification in a tornadic supercell storm is found in "Giant Electrical Storms" (Vonnegut and Moore, 1958), a work inspired by Vonnegut's personal observations of the renowned Worcester, Massachusetts storm in June 1953. This event strongly influenced Vonnegut's career as a scientist, as it stimulated his early thinking about the role of convection in the electrification of storms (Vonnegut, 1953) and the relationship between electricity and tornadoes (Vonnegut, 1960). Vonnegut and Moore (1958) also drew important attention to issues that remain with us today in the context of severe thunderstorms: (1) the extraordinarily high flash rates dominated by intracloud lightning; (in Vonnegut's words, the Worcester storm was "going like gangbusters" as it went out to sea late that evening); (2) the extraordinary updraft velocities ( $>100 \mathrm{~m} / \mathrm{s})$ inferred from simple parcel theory considerations; (3) the possible inconsistency between the observed radar cloud top height and conventional pseudoadiabatic parcel theory; (4) the evidence for electrification and lightning in a large region of the upper storm, likely devoid of supercooled water-an essential ingredient for the presently favored precipitation mechanism for thunderstorm electrification; and (5) the possibility of a negatively charged cloud top in this superlative storm. Several of these issues will be revisited later in this paper.

The Worcester storm studied by Vonnegut and Moore (1958) was also one of three major events in 1953 that together focused national attention on severe weather and its formal definition (D. Burgess, personal communication, 1998). Today, severe weather is defined by specific thresholds in wind, hail size and vorticity. All of these phenomena have close physical

\footnotetext{
- This work was sponsored by the National Aeronautics and Space Administration. The views expressed are those of the authors and do not reflect the official policy or position of the U.S. Government.

t Opinions, interpretations, conclusions, and recommendations are those of the authors and are not necessarily endorsed by the United States Air Force. Corresponding author address: Earle Williams, Massachusetts Institute of Technology, 77 Massachusetts Ave., Cambridge, Massachusetts 02139.
} 
connections with vertical drafts in deep convection, that are themselves not directly measured with scanning Doppler radars of the NEXRAD type. Cloud electrification and lightning are particularly sensitive to these drafts because they modulate the supply of supercooled water that is the growth agent for the ice particles (ice crystals, graupel and hail) believed essential for electrical charge separation. For these reasons, one can expect correlations at the outset between lightning activity and the development of severe weather that may aid in understanding and predicting these extreme weather conditions. The exploration of these ideas historically has been impeded by lack of good quantitative observations. A recent review of results on severe storm electrification (Williams, 1998) indicates a general absence of cases for which total lightning activity is documented over the lifetime of a severe storm. The recent development of LISDAD (Lightning Imaging Sensor Data Application Display) (Boldi, et al., 1998; Weber, et al., 1998) has largely remedied this problem. The LISDAD has been used in central Florida to quantify the behavior of total lightning in all types of severe weather.

\section{FORMAL SEVERE WEATHER CRITERIA AND THEIR CONNECTION WITH VERTICAL DRAFTS}

Severe weather is characterized by at least one of the following three conditions, according to present National Weather Service criteria: (1) hailstones on the ground with effective diameters greater than 0.75 inches; (2) a sustained surface wind in excess of 50 knots; and (3) the occurrence of a tornado. All of these surface conditions have their seeds in vertical storm drafts, the quantity most elusive to direct observations by Doppler radar but a quantity strongly connected with cloud electrification and lightning. The systematic behavior of total lightning aloft relative to severe weather at the ground in this study warrants some discussion of these physical relationships. 


\section{Severe Hail}

Hail growth relies on particle levitation in a vertical airstream of supercooled water. Some estimates of the updraft strength required for hailstones of various diameters is therefore provided by the computation of the hailstone fall speed. Results in Figure 1 indicate that a vertical velocity of $29 \mathrm{~m} / \mathrm{s}$ is needed to levitate a hailstone with the critical 3/4-inch diameter. (Fortunately, this air speed is very close to the severe wind speed of 50 knots to be addressed in the next subsection.) The reduction in size due to melting in the fall to the ground from the $0^{\circ} \mathrm{C}$ isotherm will obviously require still larger drafts aloft to account for the critical size at the ground.

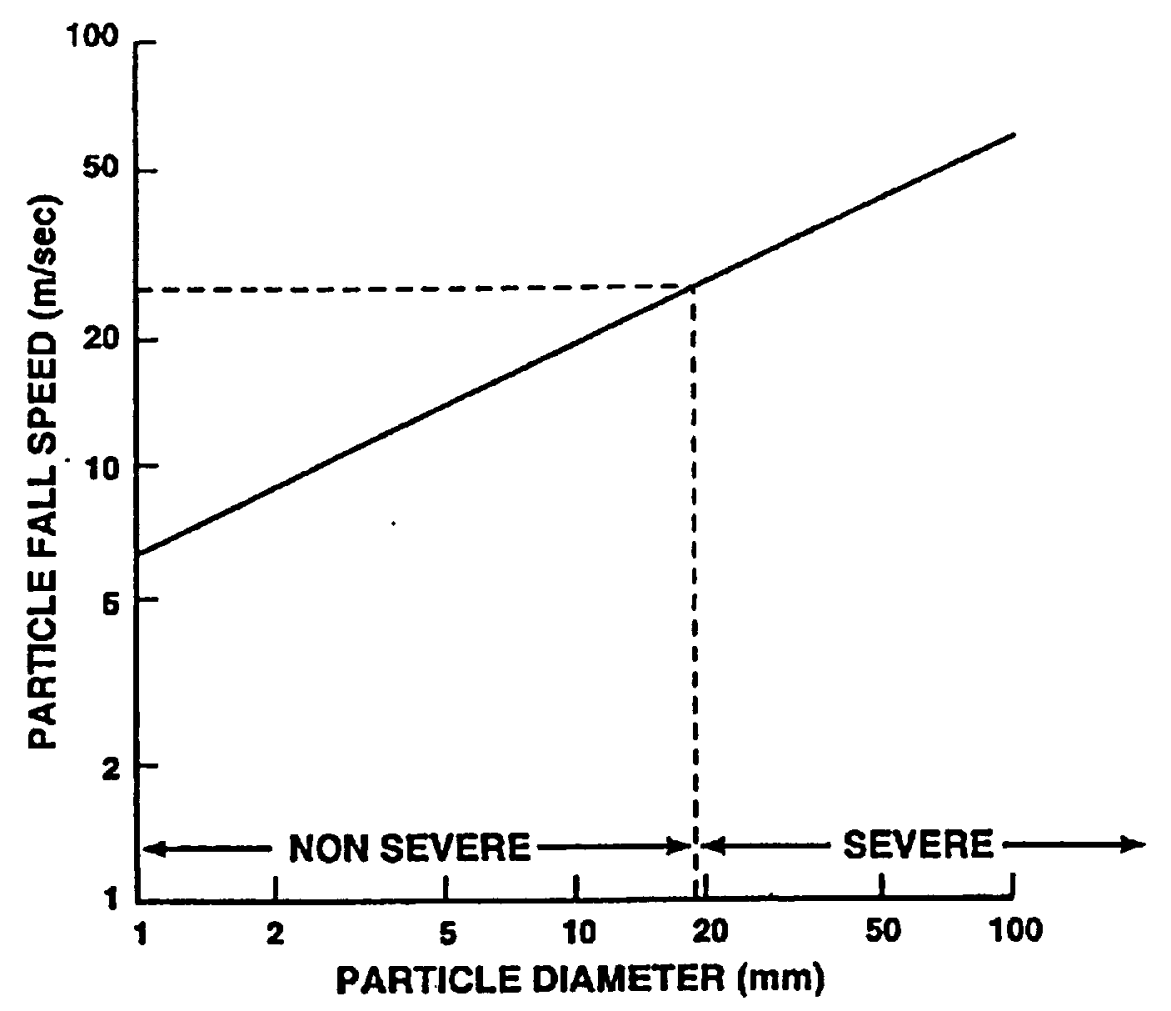

Figure 1. Fall speed of ice spheres vs. sphere diameter at an altitude of $6 \mathrm{~km} \mathrm{MSL}$ 


\section{Severe Wind}

Extreme wind at the surface in the vicinity of thunderstorms is often the result of a downdraft aloft. Mechanisms for downdrafts-gravitational loading by precipitation and cooling by evaporation and melting of condensate-have their origins in the updraft and are expected to be enhanced by stronger updrafts. The observed tendency for intracloud lightning to precede thunderstorm microbursts (Goodman, et al., 1988; Williams, et al., 1989; Malherbe, et al., 1992; Stanley, et al., 1997) is consistent with this general scenario. It is important to note however that the great majority of microburst winds do not exceed the formal 50-knot criterion and hence are not formally severe (Williams, 1998).

\section{Tornadoes}

Tornadoes are intense vortices with a dominant vertical component of angular momentum. Despite numerous theories for tornadogenesis, one feature common to all is the vertical stretching of vorticity that is modulated by the vertical gradient of vertical draft speed w (i.e., $d w / d z)$, as illustrated schematically in Figure 2. For severe storms whose vertical scale is strongly constrained by the tropopause, vertical stretching will be largely controlled by the magnitude of the drafts. Evidence will be presented later in this paper that both updrafts and downdrafts are stretching vertical vorticity. 


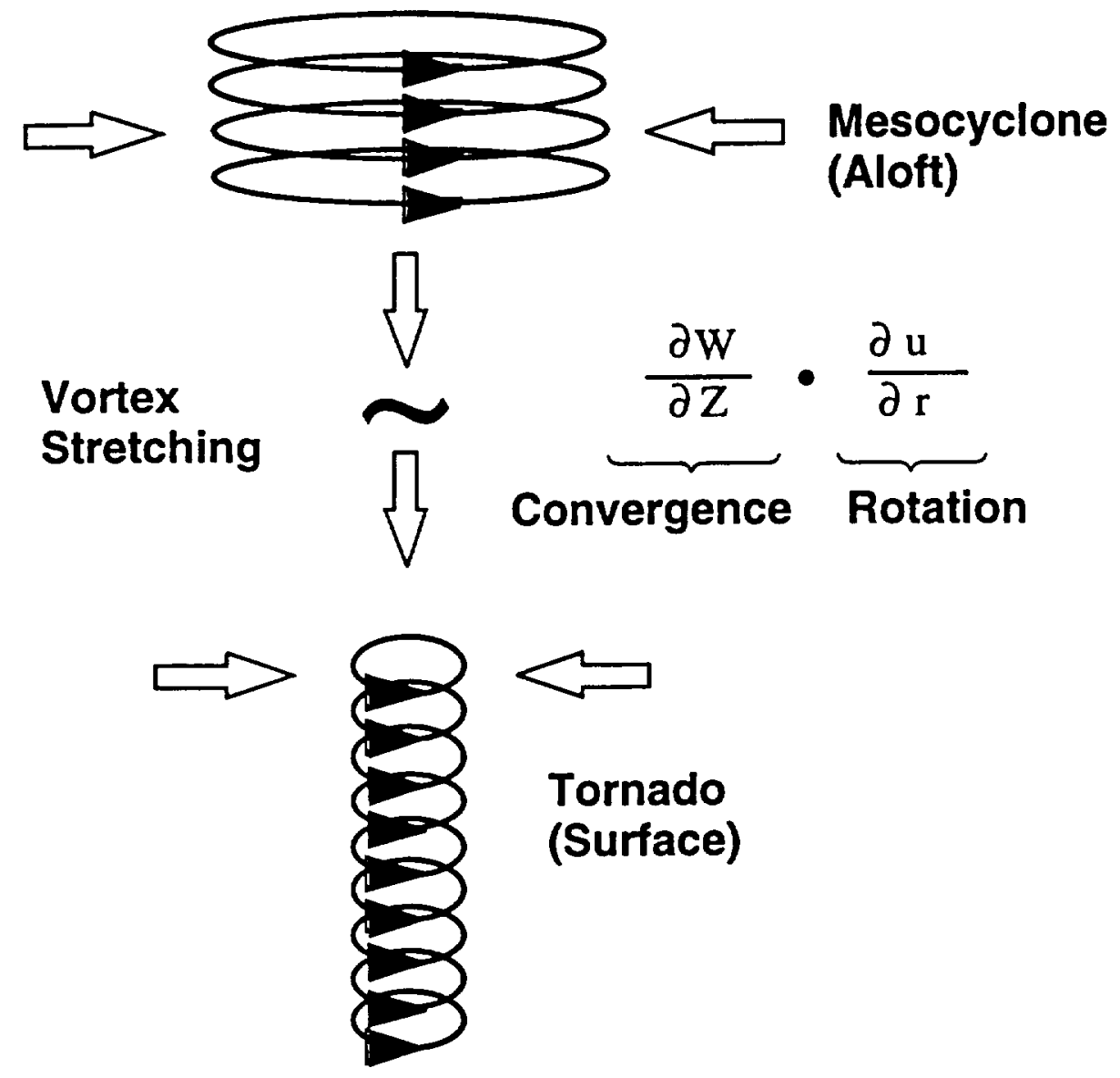

Figure 2. Illustration of the role of vertical drafts in vortex stretching.

\section{METHODOLOGY}

The observational mainstay of this study is the LISDAD system in central Florida. The original intent of LISDAD was a ground-truthing system for optically-detected lightning flashes from space using NASA's Optical Transient Detector and the Lightning Imaging Sensor. The flurry of severe weather in Florida in the spring and summer of 1997 soon made clear LISDAD's effectiveness as a tool to study severe thunderstorms (Raghavan, et al., 1997; Weber, et al., 1998). This currently operational real-time system integrates information from the prototype Integrated Terminal Weather System (ITWS), developed by Lincoln Laboratory for the Federal Aviation Administration and located in Orlando; the NWS NEXRAD radar at Melbourne; the Storm Cell Identification and Tracking (SCIT) algorithm developed by the National Severe 
Storms Laboratory (Johnson, et al); the Lightning Detection and Ranging (LDAR) system at the Kennedy Space Center (Lennon and Maier, 1991); and the National Lightning Detection Network (NLDN). The LISDAD system offers substantial improvements over the traditional short-term field experiment in the investigation of thunderstorms. The real-time, round-the-clock operation virtually guarantees capture of all interesting events. Furthermore, the direct exposure and use by operational NWS forecasters provides insights about systematic features of the observations as they occur. Finally, the different data sets that were rather laboriously assembled in the traditional field experiment after the fact are now available for integrated replay and inspection immediately following the events of interest.

The emphasis on total lightning as a diagnostic for severe weather in the LISDAD results gives the LDAR radiation data special importance. The viability of LDAR for accurately detecting and mapping both intracloud and cloud-to-ground lightning flashes has been verified through more than 25 years of operation at the NASA Kennedy Space Center (KSC). Its successful use during the TRIP (Thunderstorm Research International Program) in the 1970's (Lhermitte and Krehbiel, 1979; Lhermitte and Williams, 1985) demonstrated 50-100 meter rms errors in source locations for storms directly over $\mathrm{KSC}$, based on observations from two independent arrays of radio receivers. More recent studies in Orlando with the Office National d'Etudes and de Recherches Aerospatiale (ONERA) 3D lightning interferometer (Mazur, et al., 1997) demonstrate reliable detection of lightning at a range of $50 \mathrm{~km}$, though with an attendant degradation of location accuracy. Some LDAR radiation is detected from storms on Florida's west coast at distances from KSC exceeding $200 \mathrm{~km}$. For the rapidly migrating mesocyclones of interest in this study, analysis to distances up to about $100 \mathrm{~km}$ from $\mathrm{KSC}$ will be considered.

The LDAR data stream currently ingested by LISDAD consists of individual radio source locations $(x, y, z, t)$ that have been independently verified by the two independent arrays of receivers at KSC. This data stream is used to create an LDAR flash rate, a measure of the total flash rate for individual thunderstorm cells identified by SCIT. In this procedure, any source that 
occurs within $300 \mathrm{msec}$ and a distance $D(r)$ of a previous source is placed into the same flash as the previous source. The function $D(r)$ reflects both the typical size of storm cells and the decreasing accuracy of the LDAR system as the range ( $r$ ) from the LDAR system increases. For sources close to the LDAR network, $D(r)$ is $5 \mathrm{~km}$ and reflects the size of thunderstorm cells. For sources far from the LDAR network, $D(r)$ primarily reflects the accuracy of the LDAR system and is $30 \mathrm{~km}$. A flash can remain active for up to 5 seconds. The number of flashes generated from a set of sources is not very sensitive to the exact values of the distance window $D(r)$ or the time window $(300 \mathrm{msec})$. Experiments were performed wherein these values were doubled, with less than a 20 percent change in the number of flashes generated from a given set of sources. This indicates that the flashes are relatively compact in space-time coordinates. Many of the flashes (more than 10 percent) are composed of just a single source. Such flashes have been given the name 'singletons'. The percentage of all LDAR flashes that are singletons increases from 12 percent to 30 percent as the distance from the LDAR network to the flash increases from within $25 \mathrm{~km}$ to greater than $50 \mathrm{~km}$. Further details can be found in a recent paper by Boldi, et al (1998).

The assignment of flashes to specific storm cells is identical for NLDN ground flashes and LDAR flashes: (1) advect the positions of the cells detected by the SCIT algorithm to the current time using the ITWS track vectors provided for the respective cells; (2) assign the flash to all cells within $5 \mathrm{~km}$ of the flash location; and (3) if no cell is found within $5 \mathrm{~km}$, then assign the flash to the closest cell if that cell is within $35 \mathrm{~km}$ of the flash location. Using these rules, about 95 percent of the flashes are assigned to a single cell, with the remainder of the flashes being evenly split between 0 and 2 cell assignments per flash. In examining the fast-moving supercells discussed in this paper, it was discovered that rule 1 (cell advection) has a large influence on the computed minute-to-minute flash rates when cells move a distance about equal to their mean intercell spacing (20-50 km) in the time required for the NEXRAD radar update (five minutes). 
For more detailed analysis of the storm structure in the vertical beyond the real-time processing capability of LISDAD, the original Melbourne Doppler radar data have been analyzed after the fact. This includes the hand extraction of maximum reflectivity and mesocyclonic velocity on a tilt-by-tilt basis.

All truth on severe weather otherwise documented with LISDAD remote sensing is based on observer reports. This aspect of the study is judged to be the least quantitative and most susceptible to sampling limitations. Errors in the times for severe weather events are difficult to specify.

\section{GENERAL RESULTS}

Although the focus of this study is on all types of severe weather in central Florida, it is useful to begin with some more general results from LISDAD that pertain to ordinary (nonsevere) thunderstorms as well as the broad spectrum of severe weather in all seasons. The use of the same rules to compute total flash rates in all thunderstorms regardless of their size and severity helps to place the results for extreme instability and shear in context.

The pop-up box feature in LISDAD (Boldi, et al., 1998) has been used to study the lightning histories of numerous Florida thunderstorms of all types. Severe thunderstorms have been identified on the basis of surface observer reports of hail (dime size or greater), strong wind (trees blown down), or the occurrence of a tornado. Figure 3 summarizes the peak flash rates (LDAR for total lightning) for all cases. The most likely maximum flash rate, associated with small, nonsevere thunderstorms in great abundance, is in the range of 1-10 per minute. A vertical dashed line is indicated at a flash rate of $60 \mathrm{fpm}$ (1 flash per second). To a large extent, the storms are organized into nonsevere and severe categories on the basis of peak flash rate alone (with one important caveat to be discussed presently). No severe cases were found with a peak flash rate less than $60 \mathrm{fpm}$. For higher flash rates, the majority of cases were identified as severe. However, numerous cases with high flash rates (one as high as $500 \mathrm{fpm}$ ) were found with no 
confirmation of severe conditions. Some of these high flash rate cases occurred over sparsely populated areas where hail (for example) may have been missed. A few cases of high-flash-rate storms over heavily populated areas suggest that severe storm status was not attained.

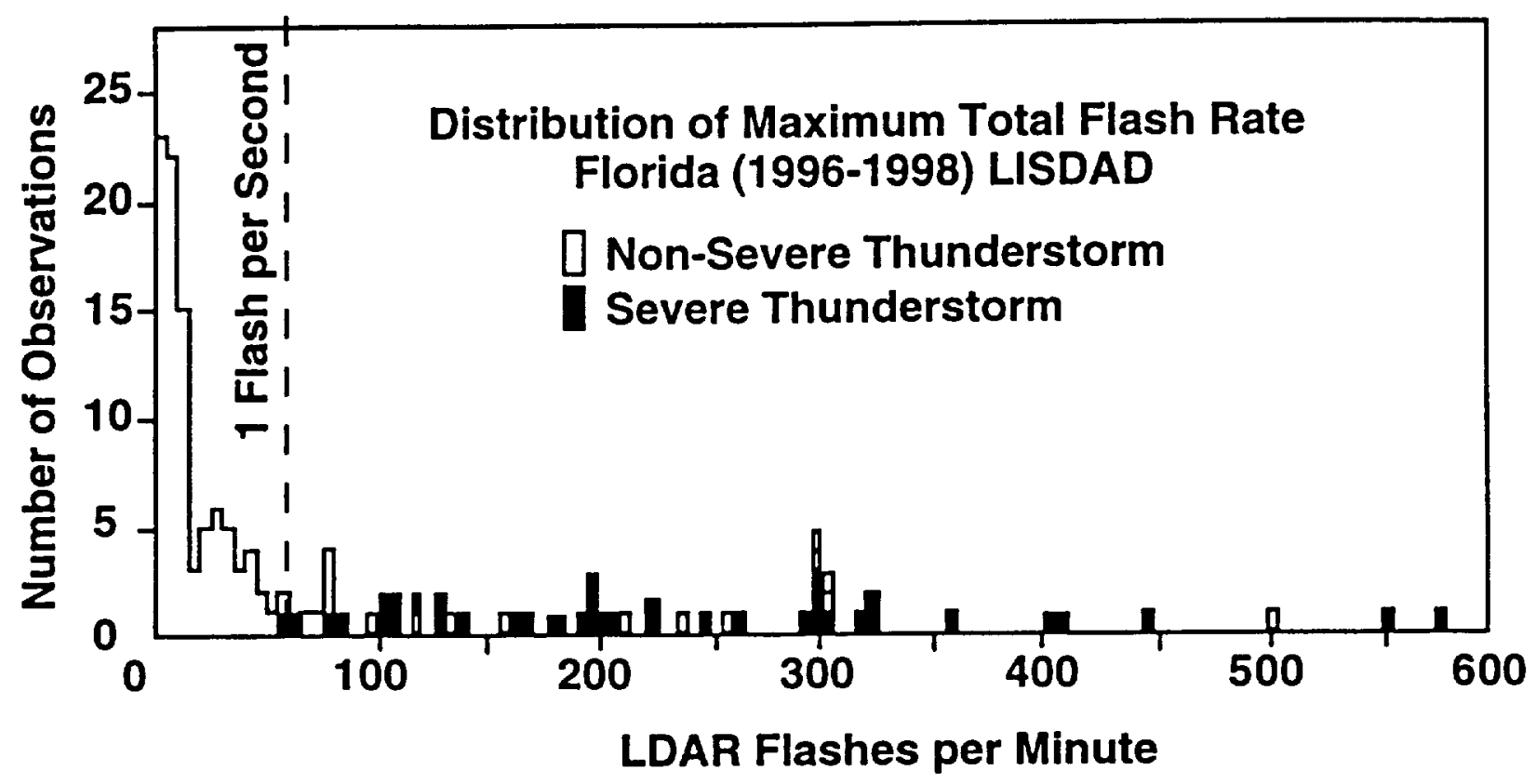

Figure 3. Peak flash rates for Florida thunderstorms based on LDAR observations.

The largest LDAR flash rates observed are in the vicinity of 500-600 fpm. The two dry season supercells discussed in Section 5 both lie in this tail of the flash rate distribution in Figure 3.

The fraction of thunderstorms found to be severe in Figure 3 is surely larger than one might find climatologically in Florida. This disproportionality is the result of the emphasis given to severe weather cases when a systematic behavior in the flash rate evolution became apparent in the early LISDAD observations.

The most obvious and systematic characteristic of severe thunderstorms is the rapid increase in intracloud flash rate 1-15 minutes in advance of the severe weather manifestation at the ground. These increases, termed lightning 'jumps', vary in magnitude from about 20 to over 100 fpm per minute. Specific examples of jumps in specific severe thunderstorms can be seen in 
Figures 6-8. The precursory nature of the lightning jump appears to pertain not just to hail but to all severe weather, including strong wind and tornadoes. A schematic history of total flash rate for a severe Florida thunderstorm is shown in Figure 4 where three characteristic times $\left(t_{0}, t_{1}\right.$, and $t_{2}$ ) are shown. Time $t_{0}$ marks the lightning jump, $t_{1}$ the peak LDAR flash rate, and $t_{2}$ the severe weather on the ground. A summary of such values for a wide range of Florida severe storm cases is shown in Table 1. On average, the recorded values are consistent with the evolution depicted in Figure 4. This table also includes values for peak flash rate (LDAR and NLDN) and estimates of the magnitudes of the precursory lightning jumps. The majority of the information in Table 1 (exclusive of surface observer reports) was obtained by playback of individual cases initially identified by NWS or Lincoln Laboratory (TTWS) personnel.

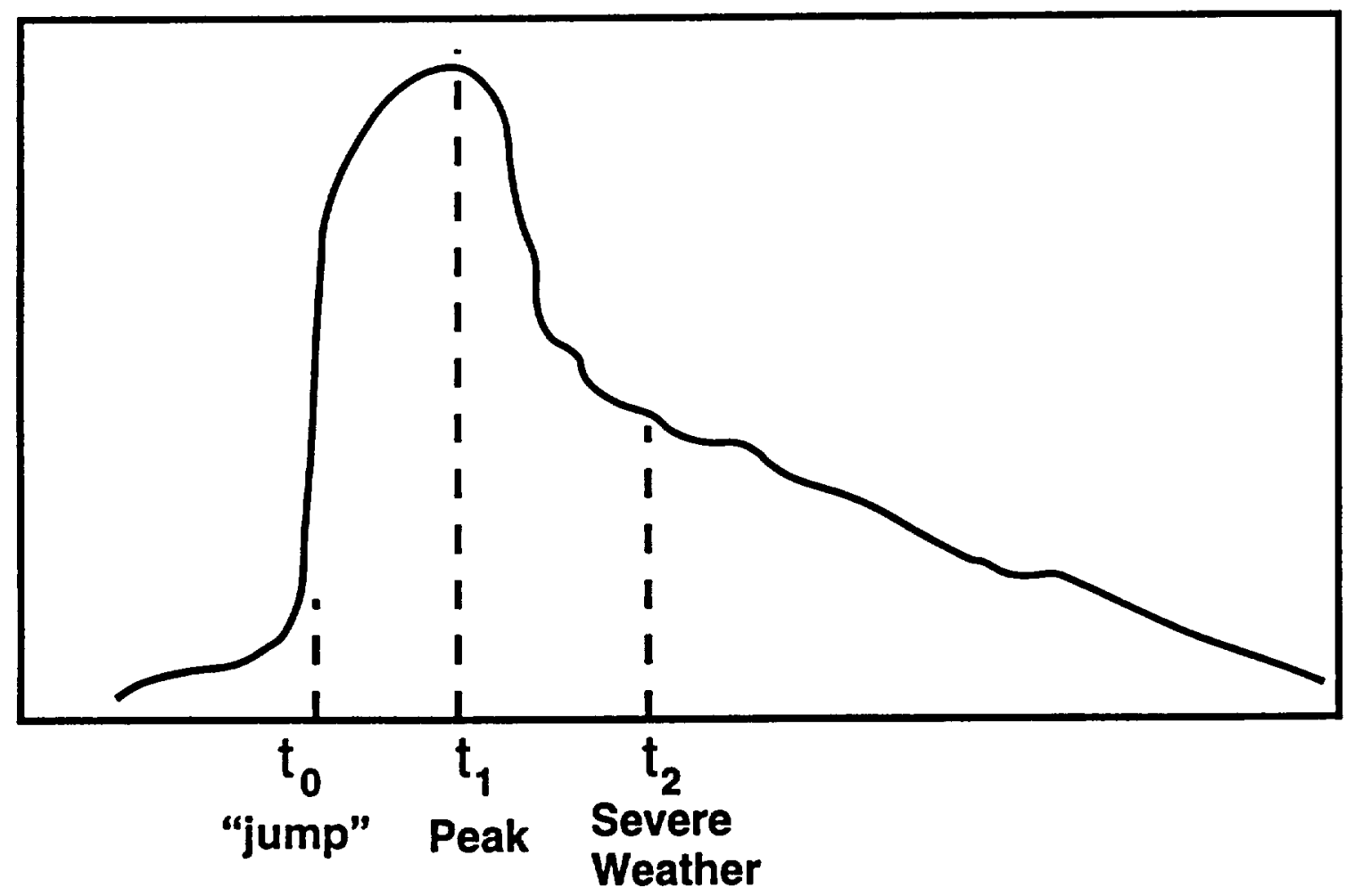

Figure 4. Schematic lightning history in a Florida thunderstorm with $t_{0}=$ jump time; $t_{1}=$ peak flash rate; and $t_{2}=$ time of severe weather. Based on calculations of mean time differences from Table $l_{\text {, if }} t_{0}=0$, then $t_{1}=7.4 \mathrm{~min}$ and $t_{2}=16 \mathrm{~min}$. 
The existence of lightning jumps is perhaps the most obvious departure from steady-state behavior for the severe thunderstorms studied. The noted association between enhanced electrification and the growth of ice particles aloft in the mixed-phase environment would suggest that the jumps are an accompaniment of strong upsurges in air motion aloft. LISDAD evidence supports the idea that the upsurges are linked with the growth of large hail. Figure 5 shows the magnitude of the lightning jump versus the maximum hailstone diameter reported on the ground for all hail cases in Table 1 observed with LISDAD. The positive correlation here supports a physical connection with stronger electrification associated with stronger upsurges and larger hail. Rough extrapolation downward to the millimeter-sized graupel characteristic of ordinary non-severe thunderclouds suggests lightning jumps less than $10 \mathrm{fpm}$ per minute, consistent with observations.

The systematic flurry of intracloud lightning activity prior to tornadoes and waterspouts in this study (Table 1) and in Goodman, et al (1998), is not without precedent. Taylor identified peak intracloud flash rates 10-15 minutes prior to some tornadoes in the 1970s (W. Taylor, personal communication, 1996). MacGorman (1993) documented a maximum in intracloud lightning prior to the Binger tornado in 1986. The similar lightning signatures for both tornadoes and waterspouts in the study lead us to draw no particular physical distinction between these two phenomena. 


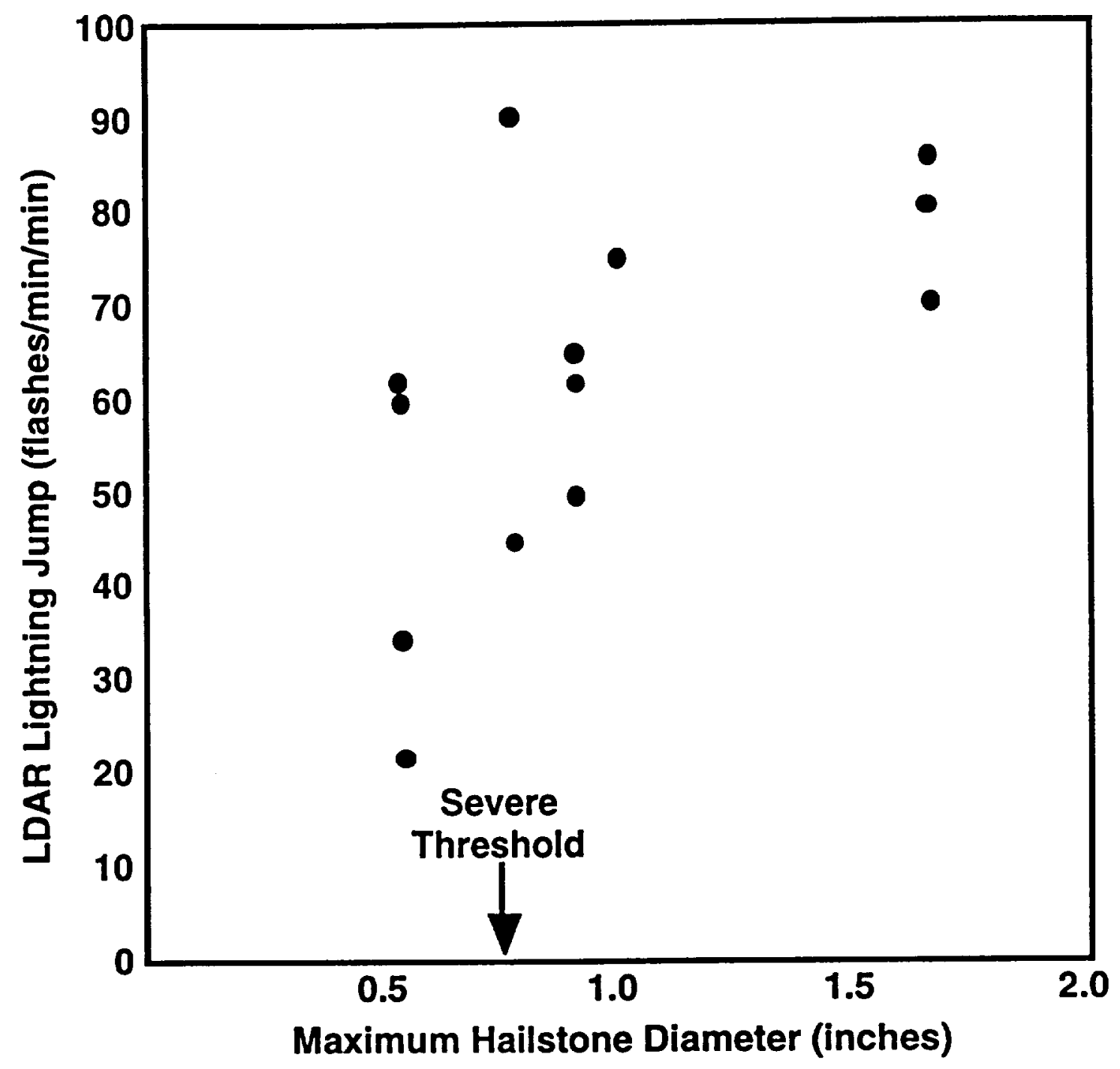

Figure 5. Lightning 'jump' vs. maximum hailstone size. These results are drawn from Table 1. 
Table 1.

LISDAD Severe Storm Summary

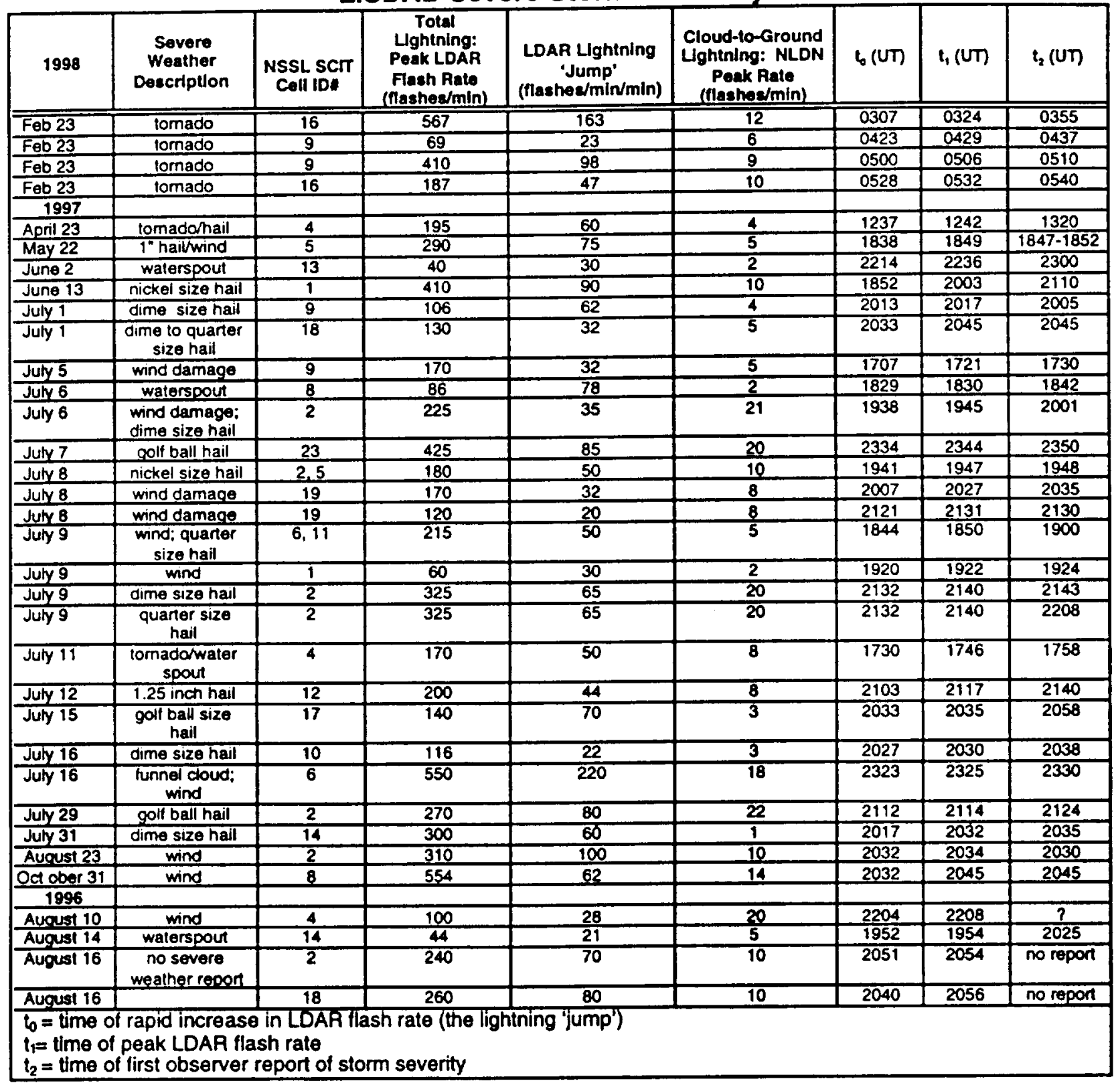

\section{CASE STUDIES}

The systematic evolution of events depicted schematically in Figure 4 is now demonstrated

for three specific cases drawn from Table 1: a hail case (May 22, 1997), a wind case (Oct. 31, 
1997), and a tornado case (Feb. 23, 1998). The purpose of these comparisons is further clarification of the physical basis of the precursor signals in total lightning.

The evolution of total flash rate and maximum differential velocity at low levels for the May 22, 1997 Orlando hail storm are shown in Figure 6. Isolated convection developed shortly after noon local time to the northwest of Orlando International Airport on this day. Within the next hour, new growth took place throughout the terminal area. The storm in question was too far from Melbourne to disclose the outflow history with the NEXRAD radar, and so the Orlando Terminal Doppler Weather Radar (TDWR) was used for this purpose. Richard Ferris, the ITWS site manager, observed oblate hailstones with diameters in the range of $3 / 4$ inch to one inch at the site in the interval 1847-1852 UT, as shown in Figure 6. The strongest outflow of the day (72 knots) was recorded by the TDWR at 1856 UT within $8 \mathrm{~km}$ of Ferris's location. This storm therefore took on severe status on the basis of both the hail and the microburst wind. 
$300139-1$
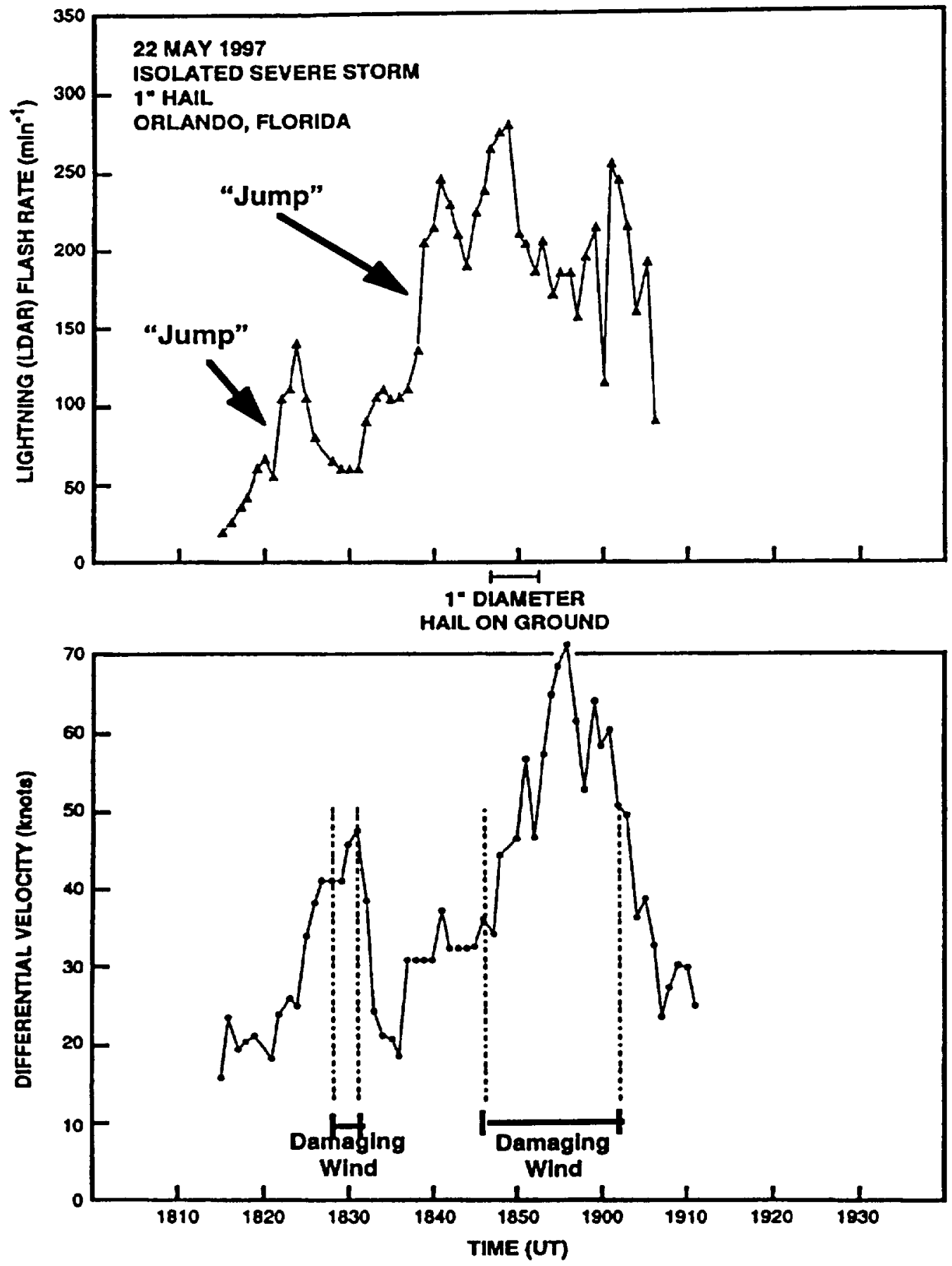

Figure 6. May 22, 1997 hailstorm with severe microburst near Orlando.

a. history of total lightning flash rate, and

b. history of differential radial Doppler velocity at the surface. 
The lightning 'jump' phenomenon was recorded by LISDAD prior to both microbursts (at 1821 UT and 1838 UT), with the second, larger jump ( 75 fpm per minute) preceding the arrival of hail by about nine minutes. It is interesting that the large hail precedes the maximum outflow by four to seven minutes, a possible suggestion that the loading and melting effects of the smaller-size precipitation are playing the major role in forcing the microburst, and the large hail fell out early on account of its significantly larger fall speed. The seven-minute lead times between peak flash rate and peak outflow agree very well with results for non-severe storms (Goodman, et al., 1988; Williams, et al., 1989; Laroche, et al., 1991; Malherbe, et al.,. 1992; Stanley, et al.,. 1997), suggesting a similar physical basis for the precursor in both types of storms. The peak LDAR flash rate prior to the hail and large microburst is 275 flashes/minute, substantially larger than values characteristic for nonsevere storms (Figure 3).

The selection of case studies from Table 1 for wind and tornado manifestations of severe weather has a twofold purpose in this study: (1) to explore the vertical development of the storm and its connection with total lightning precursors to severe weather and (2) to shed further light on the distinction between supercells that do and do not produce tornadoes, a long-standing problem both scientifically and operationally (Burgess, et al., 1993). Improved Doppler radar observations (Burgess, et al., 1993) have led to the realization that the majority of supercell mesocyclones do not evolve to tornadoes. A challenging issue is the identification of physical conditions that make the difference. With this challenge in mind, two electrically extreme supercell mesocyclones in the Florida dry season were selected from the LISDAD archive from Table 1 to compare-one on February 23, 1998 (that produced an F3 tornado) and another on October 31, 1997 (for which wind damage was reported, but no tornado). Selected parameters for comparisons of these two cases are shown in Table 2. Included in this Table are values for tropopause overshoot and inferred maximum updraft speed, following like calculations made initially by Vonnegut and Moore (1958). The numbers are for the most part quite similar, thereby emphasizing the subtlety of the distinction between supercells that do not produce tornadoes. For 
example, the peak LDAR flash rates agree to within 10 percent and are both extraordinarily high. It is possible that the use of the same (nonsevere) storm rules leads to an overcounting of flashes. It is worth noting, however, that both estimates are less than the value for stroke rate estimated by Vonnegut and Moore (1958) for the Worcester, Massachusetts, tornadic storm (600-1200 strokes per minute), the only visual observation of stroke rate in a night time supercell.

Histories of radar reflectivity and mesocyclonic rotational velocity in time-height format, together with the lightning (LDAR and NLDN ground flashes) evolutions for the two cases are shown in Figures 7 and 8 . The storm intervals containing the largest lightning jump, maximum flash rate, and most intense vertical development are included in both cases, and the overall storm tracks are also shown in Figures 7 and 8 . The magnitude of the lightning jump showed the largest contrast between the two cases among all parameters in Table 2, with the tornadoproducing case showing a substantially larger value (160 fpm/min). Neither storm was sufficiently close to the Melbourne radar to enable observation of concentrated low-level vorticity (i.e., the tornado). These time-height comparisons reveal substantially more about the differences between the two cases than the parameter comparisons in Table 2. 

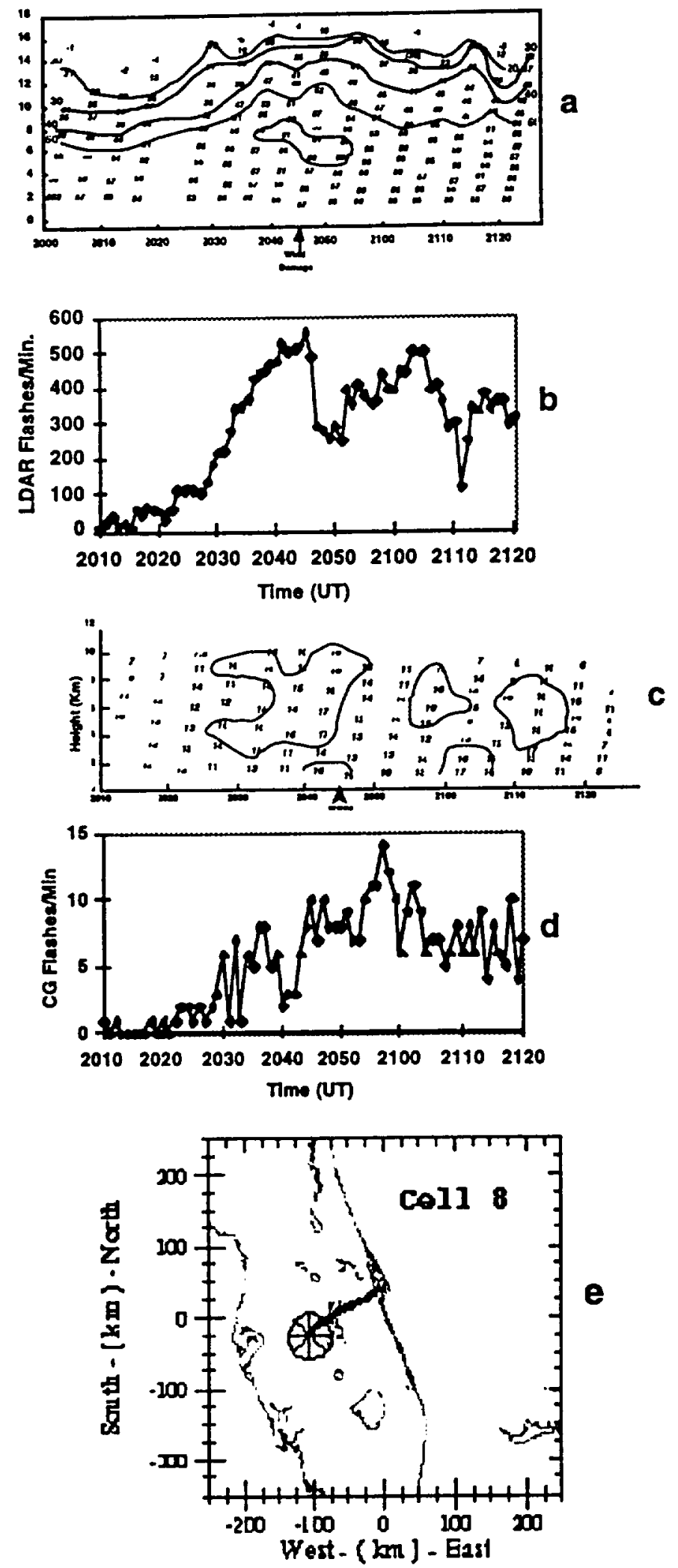

Figure 7. October 31, 1997 supercell with severe wind (Polk County): (a) Time-height plot of maximum radar reflectivity (dBZ), (b) History of cloud-10-ground flash rate. (c) Time-height plot of maximum mesocyclonic rotational velocity $(\mathrm{m} / \mathrm{s})$, (d) History of total lightning flash rate, and (e) Florida map showing supercell storm track. 

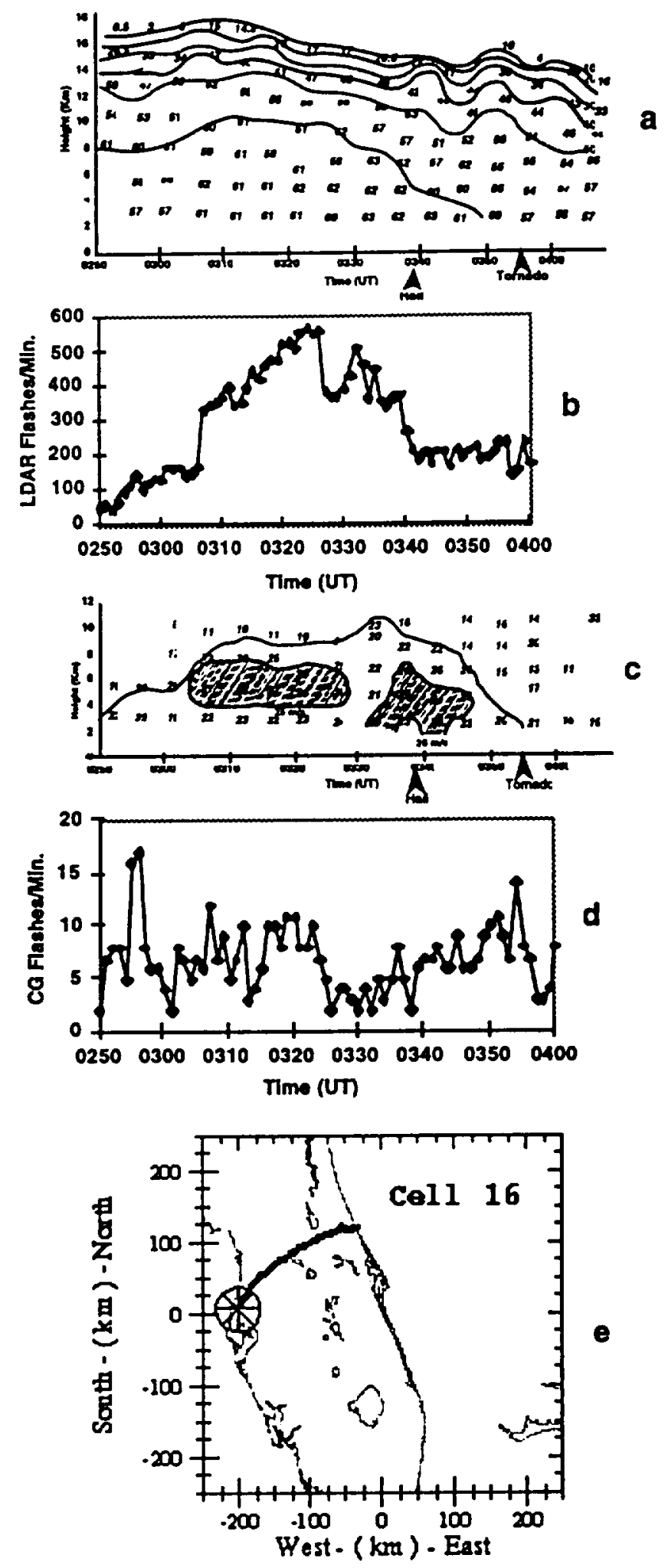

Figure 8. February 23, 1997 supercell with F3 tomado (Volusia County): (a) Time-height plot of maximum radar reflectivity (dBZ), (b) History of cloud-to-ground flash rate, (c) Time-height plot of maximum mesocyclonic rotational velocity ( $\mathrm{m} / \mathrm{s})$, (d) History of total lighining flash rate, and (e) Florida map showing supercell storm track. 
Table 2.

Comparison of Selected Parameters for Two Florida Supercells

\begin{tabular}{|c|c|c|}
\hline Parameter & 31 Oct 97 & 23 Feb 98 \\
\hline pseudoadiabatic CAPE & $1540 \mathrm{j} / \mathrm{kg}$ & $2140 \mathrm{j} / \mathrm{kg}$ \\
\hline tropopause height & $12.9 \mathrm{~km}$ & $12.7 \mathrm{~km}$ \\
\hline melting level height & $4.0 \mathrm{~km}$ & $3.8 \mathrm{~km}$ \\
\hline maximum LDAR flash rate & $554 \mathrm{fpm}$ & $567 \mathrm{fpm}$ \\
\hline maximum NLDN flash rate & $14 \mathrm{fpm}$ & $17 \mathrm{fpm}$ \\
\hline lightning 'jump' & $60 \mathrm{fpm} / \mathrm{min}$ & $160 \mathrm{fpm} / \mathrm{min}$ \\
\hline maximum IC/CG ratio & -230 & -200 \\
\hline maximum radar cloud top & $16-17 \mathrm{~km}$ & $17.18 \mathrm{~km}$ \\
\hline tropopause overshoot & $3-4 \mathrm{~km}$ & $4-5 \mathrm{~km}$ \\
\hline inferred maximum updraft speed & $60-80 \mathrm{~m} / \mathrm{s}$ & $80-100 \mathrm{~m} / \mathrm{s}$ \\
\hline $\begin{array}{l}\text { diameter of } 30 \mathrm{dBZ} \text { core } \\
\text { at } 7 \mathrm{~km}\end{array}$ & $22 \mathrm{~km}$ & $30 \mathrm{~km}$ \\
\hline Helicity $(0-3 \mathrm{~km})$ & $184 \mathrm{~m}^{2} / \mathrm{s}^{2}$ & $350 \mathrm{~m}^{2} / \mathrm{s}^{2}$ \\
\hline $\begin{array}{l}\text { mesocyclone maximum } \\
\text { rotational velocity }\end{array}$ & $19 \mathrm{~m} / \mathrm{s}$ & $28 \mathrm{~m} / \mathrm{s}$ \\
\hline $\begin{array}{l}\text { typical mid-level } \\
\text { mesocyclone diameter }\end{array}$ & $5-9 \mathrm{~km}$ & $5-8 \mathrm{~km}$ \\
\hline supercell translational speed & $50-80 \mathrm{~km} / \mathrm{hr}$ & $90-100 \mathrm{~km} / \mathrm{hr}$ \\
\hline hail (?) & no hail reported & 3/4-inch hail \\
\hline tomado (?) & $\begin{array}{c}\text { no } \\
\text { (wind damage only) }\end{array}$ & yes $(F 3)$ \\
\hline
\end{tabular}

In comparison with ordinary airmass thunderstorms (Lhermitte and Krehbiel, 1979; Lhermitte and Williams, 1985; Goodman, et al., 1988; Williams, et al., 1989), these supercells are far closer to a dynamical steady state in their vertical development. And yet the observations show in both cases that the unsteady features are of central importance in signaling severe 
conditions on the ground. The total lightning is perhaps the least steady feature of supercell evolution, with substantial lightning jumps (in the LDAR flash rate) coinciding with explosive vertical development (2020-2040 UT on Oct. 31 and 0305-0320 UT on Feb. 23) that are again precursory to severe weather (at 2045 UT on Oct. 31 and at 0355 UT on Feb. 23). The upward growth at mid-levels (and in particular in the mixed phase region where the strongest charge separation is expected) clearly coincides with the enhancement in mid-level rotation, presumably by stretching of vertical vorticity in the updraft at mid- and upper levels. In both cases, the maximum in rotational velocity aloft is sustained to the time of maximum LDAR flash rate (2045 UT on Oct. 31 and 0324 UT on Feb. 23). Unlike the behavior of many non-severe thunderstorms (Byers and Braham, 1949; Williams, 1985a), the peak flash rate does not coincide with the maximum radar cloud top height. Agreement is better between the vertical extent of radar reflectivity in the mixed phase region at lower levels, consistent with the idea that supercooled water is a fundamental ingredient in the electrification process. This leaves unresolved the question raised by Vonnegut and Moore (1958) concerning the electrical role of the large quantity of ice particles at altitudes above the mixed phase region in supercell storms. Present laboratory simulations (Takahashi, 1978; Saunders, et al., 1991) do not extend to this temperature region. Following the maximum in total flash rate in both cases, an abrupt drop in flash rate occurs, suggesting a reduction in updraft strength with an attendant reduction in rotational velocity. Severe wind is reported at the surface for the Oct. 31 case, but no severe report was logged for Feb. 23 at the equivalent time.

Shortly after the abrupt diminishments in flash rate, in both cases, a secondary maximum in rotational velocity is observed (2057 UT on Oct. 31 and 0337 UT on Feb. 23) associated with the most strongly descending reflectivity contours (and declining reflectivity within the respective mesocyclonic cores), indicative of possible restretching of the vorticity, but in this case by a downdraft rather than an updraft. 
At this juncture, the behavior of the two cases diverges. The flash rate for Oct. 31 rebuilds after its short-term decline, whereas the flash rate for Feb. 23, that has dropped to a lower relative level, does not recover. The mid-level reflectivity for Oct. 31 is sustained, whereas for Feb. 23 at mid level, reflectivity contours continue the descent that began near the time of cloud top apogee (0310 UT). An F3 tornado is observed at 0355 UT (with a notable diminishment of rotational velocity aloft) in the latter case, but no further severe weather is observed in the time frame shown for the Oct. 31 supercell.

The lightning discussion has thus far centered on the LDAR information on account of the demonstrated connection with storm vertical development. The sustained lightning jumps that stand out clearly in the LDAR history are hardly present in the NLDN ground flash history, and the general level of activity is less than the inferred intracloud development, often by more than tenfold.

Some tendency is noted for suppressed ground flash activity at times of elevated intracloud activity (2040 UT on Oct. 31 and 0330 UT on Feb. 23), suggesting a competition between lightning types for a common source of charge (Williams, 1989; MacGorman, 1993; Williams, 1998).

\section{DISCUSSION OF TOTAL LIGHTNING RATE}

The flash rates and lightning 'jumps' recorded in Figure 3 and in Table 2 in severe Florida thunderstorms are extraordinarily large in comparison with ordinary non-severe storms. This possibly controversial result and the general strategy in defining a storm's lightning activity therefore deserve some discussion. A central issue in this context is the physical nature of a lightning flash. Though complicated and still poorly understood (Bernard Vonnegut's pointed quote on this topic: "What theorist would have predicted lightning?"), the lightning flash is a well-defined physical entity, supported by numerous measurements. A flash is a connected plasma whose electrical conductivity is everywhere larger than the air dielectric in which it is 
embedded. By 'connected' we mean that at any instant in the flash's lifetime, every pair of points within the flash are linked by some path with elevated electrical conductivity. For optical measurements with limited sensitivity, a flash may appear to cease in the dark interstroke interval. However, evidence from field change measurements and radar (Hewitt, 1957; Williams, et al., 1989) support the idea that electrical current continues to flow during this interval and the flash is sustained. As noted by Heckman and Williams (1989) and Mazur, et al. (1997), continued growth of the flash somewhere in space into the surrounding electric field is required for flash sustenance.

Problems naturally arise when a flash is to be documented with inadequately sampled optical or if measurements, such as the LDAR maps of flashes discussed here. If the lightning flash radiated continuously above the measurement noise level as it progressed in space, and if the measurement sampling were continuous in time, the accurate depiction of all flashes following the above definition would be straightforward. In practice, lightning does not radiate strongly at all times, and furthermore, the LDAR sampling and processing is incomplete, with a maximum sample rate of $10 \mathrm{kHz}$. These limitations force the selection of rather simple space and time criteria (but nonetheless, criteria consistent with statistical information on the durations and extents of lightning flashes) in defining flashes as described in Section 3.

This sampling limitation for flash definition is strongly aggravated when the flash rate increases to the point where the interflash interval is comparable to or less than the flash duration and overlap in space and time is prevalent. This study has shown that this condition is very common in severe weather. This difficulty with the interpretation of LDAR radiation sources has also appeared recently in the analysis of optical pulses observed by NASA's Lightning Imaging Sensor (LIS) in space (H. Christian and D. Boccippio, personal communication, 1998). These problems are best appreciated with some simple pictures of flashes within clouds. 
Three possible scenarios for the occurrence of lightning flashes in active storm 'cells' are illustrated in Figure 9. Here we have assumed (for lack of a more strongly supported alternative) that every lightning flash is a double-ended 'tree' (Mazur, et al., 1997). Figure 9(a) depicts a situation with a single flash without overlap in either space or time. Figure 9(b) shows flash activity in different regions of space but overlapping in time. Finally, Figure 9(c)shows a scenario with overlapping flashes in both space and time.

Figure 9(a) is the usual picture for an ordinary nonsevere thunderstorm in which the charging zone and breakdown region are highly localized and in which the interflash interval is larger than the flash duration. An electrically stressed spark gap presents the same situation. Overlapping flashes are impossible in such a case, as breakdown prevents the occurrence of new breakdown to form the next flash. One possible flaw in the grouping algorithm described in Section 3 is the inadvertent decomposition of single large flashes into multiple smaller ones.

Figure 9 (b) shows a possible scenario for a high flash rate supercell with heterogeneous conditions in both particle charging and in dielectric strength, that leads to simultaneous flashes in different regions. In storms of this kind characterized by extremes in draft strength, liquid water content and ice particle size, the strongly heterogeneous conditions in microphysical growth are obvious. If such conditions are linked with particle charging (Baker, et al., 1987; Williams, et al., 1991; 1994), then we can expect heterogeneous charging. If large ice particles are influential in weakening the dielectric strength of the upper storm and aiding in the initiation of lightning flashes, we can expect multiple breakdown. The SCIT cell identification procedure in this study frequently identifies the entire supercell as one 'cell' (with one pop-up box history). These cells are often 20-30 km in diameter (Table 2) and 15-17 km deep. The substructure of these cells is readily apparent in the radar observations (not shown). 

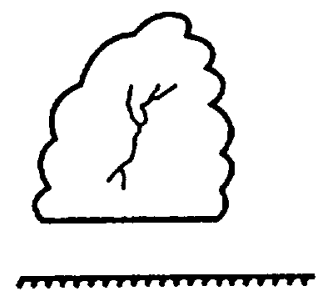

-

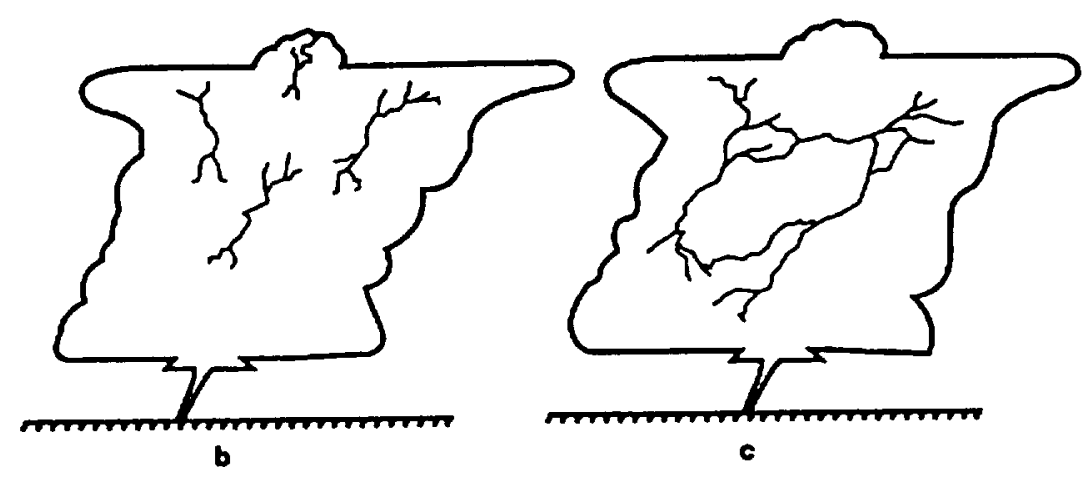

Figure 9. Lightning configurations in (a) small storm with no flash overlap in space or time, (b) severe storm with flash overlap in time but not in space, and (c) severe storm with flash overlap in space and in time.

Lightning flashes that overlap in space [as in Figure 9(c)] may not seem a likely possibility for reasons advanced in the earlier discussion of the spark gap. However, the thunderstorm is a continuous dielectric that is continuously charged. In the case of solid dielectric materials (Williams, et al., 1985b) charged continuously with an external electron beam, individual discharges occasionally overlapped in space. It is not clear to what extent this happens in severe weather, but if it does, it would present the most difficult problem of flash distinction.

One could escape the flash overlap problem entirely by abandoning the grouping of LDAR sources into flashes described in Section 3 and monitoring the LDAR source rate alone as a measure of storm electrical activity. We have not followed this approach for one major reason: the characterization of the lightning activity is then dependent on the sensitivity of the detection system (LDAR, in the present context) and on the distance between lightning and detector. If the system is sufficiently sensitive to record only one source per flash, then we achieve the desired total flash rate. A characterization of lightning activity that is independent of measurement system is clearly preferable. Most previous results on electrical activity in severe weather (reviewed in MacGorman, 1993 and Williams, 1998) are difficult to compare quantitatively with the present results because insufficient information is available on the physical process being monitored and counted. This problem may not be so serious for an optical sensor in space (e.g.., 
the Lightning Imaging Sensor) that maps optical pulses from lightning in storms all over the world, but is almost surely a problem for surface measurements on different storms in different locales.

One objection to the use of 'flash' in quantifying lightning activity is the variable nature of this unit in energy and charge moment, to name just two physical properties. Indeed, the charge moments of flashes we define by LDAR groupings may vary from a fraction of a coulombkilometer (for delicate intracloud flashes high in the storm) to several thousand coulombkilometers for the large 'spider' lightning in mesoscale convective systems (Williams, 1998; Huang, et al., 1998). We view this variability as an inevitable consequence of the meteorological variability. Furthermore, the history of lightning studies gives us a much better feel for energy and charge moment of flashes than for the physical processes with which individual LDAR sources may be associated.

For all of these reasons, we prefer to quantify electrical activity as a flash rate in the severe weather cases examined. A single rule for grouping LDAR sources into flashes is applied in all cases. The flash rates we obtain for nonsevere thunderstorms are reasonable ones (Figure 3). Though errors may arise due to space/time overlap in the severe regime when the flash rates are quite high, the values obtained are not implausible. As mentioned earlier, Bernard Vonnegut estimated a lightning stroke rate of 600 per minute in a supercell storm. This value is on the high end of values documented in this study in Figure 3.

\section{CONCLUSIONS}

The LISDAD system has revealed a remarkably consistent pattem of total lightning behavior for severe Florida thunderstorms, with strong upsurges prior to severe weather in all categories (wind, hail and tornadoes), in both the wet and the dry seasons. The updraft appears to be causal to both the extraordinary intracloud lightning rates and the physical origin aloft of the severe weather at the surface. The supercell comparison has disclosed deep reservoirs of vertical 
mesocyclonic angular momentum (to $10 \mathrm{~km}$ altitude), with indications of vortex stretching by both updrafts initially and by downdrafts at later stages. These cases and additional tornado/waterspout cases considered by Goodman, et al (1998) and Hodanish, et al (1998) are consistent in showing that pronounced departures in dynamical steady state are needed for tornadogenesis. In particular, a slumping of the cloud and attendant diminishment in total flash rate after the initial lightning jump appear necessary to concentrate vorticity near the surface. Continued examination of Florida null cases (i.e., mesocyclones without tornadoes) with the LISDAD are needed for further clarification of mechanisms.

\section{ACKNOWLEDGMENTS}

Leslie Mahn prepared the manuscript with patience and precision. Discussions on severe weather with D. Burgess, C. Doswell, D. MacGorman R. Markson, E. Rasmussen, and W. Taylor are greatly appreciated. Richard Ferris provided valuable on-site observations of many of the Florida storms. P. MacKeen, Travis Smith, and M. Eilts provided guidance on the NSSL algorithm. The LISDAD project has been supported by Jim Dodge of the NASA Earth Science Enterprise under Contract H-23725D. We thank R. Markson for additional support to Lincoln Laboratory on a NASA STTR project. 


\section{REFERENCES}

Baker, B., M.B. Baker, E.R. Jayaratne, J. Latham, and C.P.R. Saunders, The influence of diffusional growth rates on the charge transform accompanying rebounding collisions between ice crystals and soft hailstones, Quart., J., Roy. Met. Soc., 113, 1193-1215, 1987.

Boldi, R., E. Williams, A. Matlin, M. Weber, S. Hodanish, D. Sharp, S. Goodman and R. Raghavan, The design and evaluation of the lightning imaging sensor data applications display (LISDAD), 19th Conference on Severe Local Storms, AMS, 1998.

Burgess, D.W., R.J. Donaldson Jr., and P.R. Desrochers, Tornado detection and warning by radar, in The Tornado: Its Structure, Dynamics, Predictions and Hazards, ed., C. Church, D. Burgess, C. Doswell and R. Davies-Jones, AGU Geophysical Monograph 79, 1993.

Burgess, D., personal communication, 1998.

Byers, H.R. and R.R. Braham, The Thunderstorm, U.S. Government. Printing Office, June 1949.

H. Christian and D. Boccippio, personal communication, 1998.

Goodman, S.J., D.E. Buechler, P.D. Wright and W.D. Rust., Lightning and precipitation history of a microburst-producing storm, Geophys. Res. Lett., 15, 1185-1188, 1988.

Goodman, S., R. Raghavan, E. Williams, R. Boldi, A. Matlin, and M. Weber, Total lightning and radar storm characteristics associated with severe storms in central Florida, 19th Conference on Severe Local Storms, AMS, 1998.

Heckman, S.J. and E.R. Williams, Corona envelopes and lightning currents, J. Geophys. Res., 94, 13287-13294, 1989. 
Huang, E.W., E. Williams, R. Boldi, S. Heckman, W. Lyons, M. Taylor, C. Wong, and T. Nelson, Criteria for elves and sprites based on Schumann resonance observations, $J$. Geophys. Res., submitted 1998.

Hewitt, F.J., Radar echoes from interstroke processes in lightning, Proc. Phys. Soc. London, B70, 961-979, 1957.

Hodanish, S., D. Sharp, E. Williams, R. Boldi, A. Matlin, M. Weber, S. Goodman and R. Raghavan, Observations of total lightning associated with severe convection during the wet season in central Florida, 19th Conference on Severe Local Storms, AMS, 1998.

Johnson, J. T., P. L. MacKeen, A. E. Witt, E. D. Mitchell, G. Stumpf, K. Thomas, The storm cell identification and tracking Algorithm: An enhanced WSR-88D algorithm. Wea. Forecasting, 13, 1998.

Laroche, P., C. Malherbe, A. Bondiou, M. Weber, C. Engholm, and V. Coel, Lightning activity in microburst producing storms, 25th International Conference on Radar Meteorology, Paris, France, 1991.

Lennon, C. and L. Maier, Lightning mapping system, NASA CP-3106, Vol II, International Aerospace and Ground Conference on Lightning and Static Electricity, 89-1 to 89-10, 1991.

Lhermitte, R. and P. Krehbiel, Doppler radar and radio observations of thunderstorms, IEEE Tran. Geosci. Electron., GE-17, 162-171, 1979.

Lhermitte, R. and E. Williams, Thunderstorm electrification: a case study, J. Geophys. Res., 90, 6071-6078, 1985.

MacGorman, D.R., Lightning in tornadic storms: a review, in The Tornado: Its Structure, Dynamics, Prediction and Hazards, eds., C. Church, D. Burgess, C. Doswell, and R. DaviesJones, Geophysical Monograph 79, American Geophysical Union, 1993. 
Malherbe, C., J. Pigere, P. Blanchet, O. Deste, A. Bondiou, and P. Laroche, Relation Entre L'activité Electrique D'Orage et le Développement de Microbursts-Experience MIT/ONERA, Orlando, FL, 1991, RF ONERA \# B0516154P4, June 1992.

Mazur, V., E. Williams, R. Boldi, L. Maier, and D. Proctor, Initial comparison of lightning mapping with operational time-of-arrival and interferometric systems, J. Geophys. Res., 102, 11071-11085, 1997.

Perez, A.H., R.E. Orville, and L.J. Wicker, Characteristics of cloud-to-ground lightning associated with violent tornadoes, Weather and Forecasting, 12, 428-437, 1997.

Raghavan, R., S. Goodman, P. Meyer, R. Boldi, A. Matlin, M. Weber, E. Williams, D. Sharp, S. Hodanish, J. Madura, and C. Lennon, A real-time examination of the incremental value of lightning data in diagnosing convective storm characteristics, Preprints, Seventh International Conference on Aviation, Range, and Aerospace Meteorology, Long Beach, CA, AMS, 1997.

Rasmussen, E.N. and J.M. Straka, Mobile mesonet observations of tornadoes during VORTEX95, AMS Conference on Severe Local Storms, 1-5, San Francisco, CA, February, 1996.

Saunders, C.P.R., W.D. Keith, and R.P. Mitzeva, The effect of liquid content on thunderstorm changing, J. Geophys. Res., 96, 11007-11017, 1991.

Stanley, M., P. Krehbiel, and W. Rison, Lightning as a Precursor of Outflow and Downbursts from Thunderstorms, 28th Conference on Radar Meteorology, Austin, TX, American Meteorological Society, pp. 151-152, 1997.

Storm Data, NOAA (Ashville, N.C.), Vol. 39, No. 10, 1997.

Takahaski, T., Riming electrification as a charge generation mechanism in thunderstorms, $J$. Atmos. Sci., 1536-1548, 1978. 
Vonnegut, B., Possible mechanism for the formation of thunderstorm electricity, Bull. Am. Met. Soc., 34, 378, 1953.

Vonnegut, B., Electrical theory of tornadoes, J. Geophys. Res., 65, 203-121, 1960.

Vonnegut, B. and C. B. Moore, Giant Electrical Storms, in Recent Advances in Atmos. Elec., Ed., L.G. Smith, Pergamon Press, 1958.

Weber, M.E., E.R. Williams, M.M. Wolfson and S.J. Goodman, An assessment of the operational utility of a GOES lightning mapping sensor, Project Report. NOAA-18, MIT Lincoln Laboratory, Lexington, MA, 13 February, 1998.

Williams, E.R., Large scale charge separation in thunderstorms, J. Geophys. Res., 90, D4, 6013$6025,1985 a$.

Williams, E.R., C.M. Cooke, and K.A. Wright, Electrical discharge propagation in and around space charge clouds, J. Geophys. Res., 90, 6059-6070, $1985 \mathrm{~b}$.

Williams, E.R., M. Weber, and R. Orville, The relationship between lightning type and convective state of thunderclouds, J. Geophys. Res., 94, 13213-13220, 1989.

Williams, E.R., The tripole structure of thunderstorms, J. Geophys. Res., 13151-13167, 1989.

Williams, E.R., The positive charge reservoir for sprite-producing lightning, J. Atmos. Terr. Phys., in press, 1998.

Williams, E.R., S.G. Geotis, and A.B. Bhattacharya, A radar study of the plasma and geometry of lightning, J. Atmos., Sci., 46, 1173-1185, 1989.

Williams, E.R., R Zhang and J. Rydock, Mixed-phase microphysics and cloud electrification, $J$. Atmos. Sci., 48, 2195-2203, 1991. 
Williams, E.R., R Zhang and D. Boccippio, Microphysical growth state of ice particles and large-scale electrical structure of clouds, J. Geophys. Res., 99, 10787-10793, 1994.

Williams, E.R., The electrification of severe storms, AMS Monograph on Severe Storms, Ed., C.A. Doswell, in review, 1998. 